University of Nebraska - Lincoln

DigitalCommons@University of Nebraska - Lincoln

Faculty Publications, Department of Child, Youth, and Family Studies

Child, Youth, and Family Studies, Department of

2021

\title{
Food Program Participation Influences Nutrition Practices in Early Care and Education Settings
}

Bethany D. Williams

Susan B. Sisson

Irene Padasas

Dipti Dev

Follow this and additional works at: https://digitalcommons.unl.edu/famconfacpub

Part of the Developmental Psychology Commons, Family, Life Course, and Society Commons, Other Psychology Commons, and the Other Sociology Commons

This Article is brought to you for free and open access by the Child, Youth, and Family Studies, Department of at DigitalCommons@University of Nebraska - Lincoln. It has been accepted for inclusion in Faculty Publications, Department of Child, Youth, and Family Studies by an authorized administrator of DigitalCommons@University of Nebraska - Lincoln. 


\title{
Food Program Participation Influences Nutrition Practices in Early Care and Education Settings
}

\author{
Bethany D. Williams, $\mathrm{MSH}^{1}$ \\ Susan B. Sisson, PhD, RDN, CHES, FACSM, ${ }^{1}$ \\ Irene O. Padasas, $\mathrm{MA},{ }^{2} \&$ \\ Dipti A. Dev, MS, $\mathrm{PhD}^{2}$
}

\begin{abstract}
1 Department of Nutritional Science, College of Allied Health Sciences, University of Oklahoma Health Sciences Center, Oklahoma City, OK

2 Department of Child, Youth, and Family Studies, College of Education and Human Sciences, University of Nebraska-Lincoln, Lincoln, NE

Correspondence - Dipti A. Dev, MS, PhD, College of Education and Human Sciences, University of Nebraska-Lincoln, 255 Louise Pound Hall, $512 \mathrm{~N}$ 12th St,

Lincoln, NE 68588; email ddev2@unl.edu
\end{abstract}

\begin{abstract}
Objective: To determine differences by Child and Adult Care Food Program (CACFP) participation on nutrition requirements and best practices and barriers to implementing both in early care and education programs (ECEs) stratified by context (centers vs home-based ECEs).

Design: Cross-sectional survey.

Setting: Three-thousand and fourteen licensed Nebraska ECEs in 2017.

Participants: One-thousand three hundred forty-five ECEs.

Published in Journal of Nutrition Education and Behavior 53:4 (2021), pp 299-308.

doi:10.1016/j.jneb.2021.01.012

Copyright (C) 2021 Society for Nutrition Education and Behavior. Published by Elsevier Inc. Used by permission.

Accepted January 10, 2021.
\end{abstract}


Main Outcome Measures: Director-reported nutrition practices in classrooms serving children aged 2-5 years ( 8 requirements for foods served, 5 best practices for foods served, and 14 best practices for mealtime behaviors).

Analysis: Chi-square analysis adjusted for multiple comparisons.

Results: Of the sample, 86.8\% participated in CACFP, 21.7\% were center-based, and $78.3 \%$ were home-based. Overall, CACFP participation was related to the higher implementation of CACFP requirements for foods served $(P<0.004$ for all) and receiving professional development on nutrition $(P<0.012)$. In homebased ECEs only, CACFP participation was related to a higher prevalence of serving meals family style $(P=0.002)$; however, these practices had low implementation overall.

Conclusion and Implications: Findings suggest strengthening of requirements to include staff mealtime behaviors beyond service of healthful foods. Improving CACFP enrollment and including CACFP standards in state licensing requirements may be key strategies for improving nutrition practices in ECEs.

Keywords: Child and Adult Care Food Program, child care, nutrition, policies, practices

\section{Introduction}

Dietary behaviors in youth, including consumption of adequate fruits and vegetables, can promote present and future metabolic health, ${ }^{1,2}$ and the early childhood years are an important formative period for establishing lifelong dietary preferences and habits..$^{3-5}$ Early childhood care and education programs (ECEs) are promising for the promotion of health behaviors, with more than $60 \%$ of US children aged under 5 years attending ECEs in which they may spend up to 33-40 hours/ wk. 6,7 The Child and Adult Care Food Program (CACFP) offers federal funding from the US Department of Agriculture Food and Nutrition Services through reimbursing costs of healthful food items in participating care facilities serving children from low-income families; ultimate goals are to provide nutritious meals for those at highest risk of hunger and food insecurity. ${ }^{8}$ In 2018, more than 4.6 million people benefited from CACFP, with distributed reimbursement totaling more than $\$ 3$ billion dollars. ${ }^{9}$

The CACFP requires particular food groups to be served to children aged $2-5$ years, while best practices are additionally promoted through CACFP-aligned educational guidance and materials. These best practices, although not required or formally regulated, are based on federal guidelines ${ }^{10}$ with aims to promote consistency in programs 
and create a healthier overall food environment within participating ECEs. Studies report a higher quality of food and beverages served ${ }^{11-13}$ and healthier mealtime behaviors ${ }^{11}$ in CACFP-participating programs than nonparticipants. However, there has been variability in the effectiveness of program compliance with CACFP guidelines, ${ }^{12,14}$ suggesting a need to understand practice implementation and barriers nationally. Nebraska currently ranks fifth for childhood obesity in children aged 2-4 years. ${ }^{15}$ Furthermore, CACFP provides reimbursement for $86 \%$ of ECEs throughout the state. ${ }^{16}$ Therefore, this study aimed to determine differences by CACFP participation on nutrition requirements and best practices and barriers to implementing both, in Nebraska early care and education programs (ECEs) stratified by context (centers vs home-based ECEs).

\section{Methods}

\section{Study Design}

The Healthy Children, Healthy State Survey, was a cross-sectional study employed throughout the state of Nebraska in 2017 by self-administered surveys distributed to all licensed ECE facilities statewide $(\mathrm{N}=3,014)$. This study was approved by the Institutional Review Board at the University of Nebraska-Lincoln. Consent was implied with the completion and return of the survey. Detailed methods have been previously published. ${ }^{17}$

Briefly, the response rate was 54.6\%, with 1,592 surveys returned from contacted programs. Facilities were excluded from the analytic sample if they were not classified as centers or home-based ECEs (i.e., public schools and community programs) $(n=46)$ or Head Start programs $(n=56)$. Not only was the sample size limited for Head Start, but these programs have amore stringent requirement for performance standards and offer a different array of low-income family resources, ${ }^{18}$ which makes them difficult to compare with other ECE contexts. Therefore, the final study sample included 1,490 eligible ECE programs. 


\section{Survey Instrument}

The Healthy Children, Healthy State survey included an 86-item paper questionnaire distributed to ECE directors; notably, instruction included that responses should refer only to centers and classrooms serving children aged 2-5 years, and additionally indicated that if directors were unsure of an item, they could complete with the help of those most familiar with the program's classroom nutrition practices (i.e., teachers, kitchen staff, etc.). The survey included items to obtain information on the characteristics of the facility and classroom, including CACFP participation, nutrition education/training, and various information relating to CACFP-defined requirements and recommended best practices, including adherence, barriers, and difficulty of implementation. Items were drawn from previously published research with ECE providers, ${ }^{19-22}$ and were reviewed by an expert advisory panel then piloted with 3 centers and home-based ECE providers. Further details on this process have been published previously. ${ }^{23}$

The survey included 5 items to assess CACFP-required standards and 6 items to assess recommended best practices for serving foods and beverages. To determine CACFP-required standards for serving fruits and vegetables at lunchtime, 2 questions served as proxies, specifically assessing serving fruits or vegetables at least 1 time/d. The survey also included 14 items to assess CACFP-recommended best practices for mealtime behaviors, including role-modeling, child engagement, and promoting child autonomy before and during mealtime. For each statement, the respondent indicated Yes or No to whether the program was currently participating in that practice. For each of these items, providers were also asked, How difficult is it to do (or potentially do)? To assess the level of difficulty of implementation, there were 4 possible responses, including Not at all difficult, A little difficult, Kind of difficult, or Very difficult.

The questionnaire included 13 separate items to assess possible barriers to implementing requirements and best practices for serving foods and beverages, and 9 items to assess possible barriers to implementing best practices for mealtime behaviors. Options for potential barriers addressed common limitations relating to finances, time, knowledge, efficacy, and more. For each statement, the respondent indicated Yes or No to whether they considered that barrier to 
be a problem their program encounters. Finally, the survey included 4 items to assess involvement in nutrition training; the respondent indicated how regularly they received that training out of 4 possible responses, including Rarely or never, 1 time per month, 2-3 times per month, or 1 time per wk or more. In regard to professional development on child nutrition, the 4 possible responses were tailored to read Never, Less than 1 time per year, 1 time per year, or Two or more times per year. For professional development, this could include in-person or online training for contact hours or continuing education credits, but not training on food safety or food program guidelines.

\section{Statistical Analysis}

To address the primary aims of this study, Pearson chi-square test of independence was performed using SPSS (version 24.0, IBM Corp, 2016) to determine differences in best practice implementation, barriers, and difficulty level between those who do vs do not participate in CACFP, stratified by ECE context (centers vs homebased ECEs). Data are presented with the standard level of significance $(\mathrm{P} \leq 0.05)$ and after Bonferroni correction for multiple analyses. ${ }^{24}$ Adjusted $P$ values are indicated in footnotes of each table. Proportions of providers who responded Yes to whether the program was currently meeting best practices for serving food and beverages or mealtime behaviors were compared by CACFP participation; those who responded Not at all difficult for of each of these practices were also compared. Similarly, proportions of providers who responded No to experiencing barriers to best practice implementation were compared by CACFP participation, and proportion of those who do regularly engage in nutrition education were also compared.

\section{Results}

The final study sample included 1,490 respondents; after removing those with missing data on primary variables of interest ( $\mathrm{n}=$ 145), the final analytic sample included 1,345 licensed ECE programs in Nebraska; 1,168 (86.8\%) participated in CACFP (Table 1). Of the total sample, $394(21.7 \%)$ were centers, and 1,053 (78.3\%) were 
home-based ECEs. Prevalence of CACFP participation was 50.2\% and 92.1\% in centers and home-based ECEs, respectively. Centers served more children in total than home-based ECEs, and across all contexts, the majority of children attending ECEs were White. The majority of center menus were planned by directors or site supervisors, whereas in home-based ECEs, the majority were planned by the owner or child care provider themselves. Overall, implementation of nutrition practices for serving fruits, vegetables, and whole grains were relatively high across ECEs, regardless of CACFP participation and context $(78.5 \%$ to $99.5 \%)$. In contrast, implementation of recommended mealtime best practices, such as cuing children to their own satiety or refraining from using foods as a reward, were relatively low overall $(25.9 \%$ to $62.9 \%)$.

In both centers and home-based ECEs, CACFP participation was related to a higher prevalence of implementing CACFP requirements and best practices for food and beverages served and lower self-reported difficulty implementing best practices (Table 2). In centers participating in CACFP as compared with non- CACFP centers, the prevalence of implementing CACFP-required standards for foods served differed; specifically, the prevalence was approximately $8 \%$ higher for serving fruit at least 1 time, $11.3 \%$ higher for serving vegetables at least 1 time, $22.3 \%$ higher for serving skim or $1 \%$ milk, and $28.4 \%$ higher for serving only unflavored skim or $1 \%$ milk $(\mathrm{P}<0.004$ for all) in CACFP participating centers. For home-based ECEs participating in CACFP as compared with non-CACFP homes, the prevalence was approximately $1.1 \%$ higher for serving fruit at least 1 time $(\mathrm{P}=0.027)$, although this finding was not significant when considering adjustment for multiple comparison. However, prevalence was 3.1\% higher for serving vegetables at least 1 time, $27.2 \%$ higher for serving skim or $1 \%$ milk, and $30.3 \%$ higher for serving only unflavored skim or $1 \%$ milk ( $<<0.004$ for all) in CACFP-participating homes compared to non-CACFP homes when considering the Bonferroni adjustment. Notably, after considering adjustment for multiple comparison, perceived level of difficulty implementing requirements remained significantly different by CACFP participation, in home-based ECEs only ( $\mathrm{P}<0.004$ for all).

In centers and home-based ECEs, the prevalence of implementing CACFP-recommended best practices for foods served was mostly similar by CACFP participation status (Table 2). In centers specifically, 
the prevalence in CACFP-participating sites was approximately $13.3 \%$ higher for preparing cooked vegetables without fat or butter compared with non-CACFP centers $(\mathrm{P}<0.004)$. While prevalence was higher for serving lean or low-fat meat among CACFP-participating centers compared with those non-CACFP centers. However, this relationship was no longer significant when considering adjustment for multiple comparison ( $\mathrm{P}=\mathrm{0.03}$ ). Furthermore, in centers, perceived difficulty in implementing CACFP-recommended best practices did not differ by CACFP participation status. For home-based ECEs participating in CACFP compared with non-CACFP homes, the prevalence was approximately $9.5 \%$ higher for never serving sugary drinks. However, this relationship was no longer significant when considering adjustment for multiple comparison ( $\mathrm{P}=0.042)$. In addition, in homebased ECEs, CACFP participation was related to a higher prevalence of responding that the specific practice was not at all difficult for preparing cooked vegetables without fat or butter $(\mathrm{P}<0.001)$.

Child and Adult Care Food Program participation influence on perceived barriers to practice implementation for food and beverages served are presented in Table 3. For home-based ECEs participating in CACFP compared with non-CACFP homes, the prevalence of reporting not enough money to cover to cost as a barrier was approximately 15.5\% lower ( $\mathrm{P}=0.006)$. Unexpectedly, the prevalence of reporting a lack of support from other providers as a barrier was approximately 4.9\% higher in homebased ECEs participating in CACFP compared with non-CACFP homes ( $\mathrm{P}=0.033$ ). Neither relationship was significant when considering adjustment for multiple comparison.

Compared with CACFP requirements and best practices related to food and beverages served, few best practices for mealtime behaviors differed by CACFP participation (Table 4). In centers participating in CACFP, the prevalence of asking children if they are full before removing plates was approximately 8.2\% lower than non-CACFP centers $(\mathrm{P}=0.048)$. Furthermore, CACFP-participating centers experience a higher level of difficulty for role modeling eating healthy foods; specifically, in non-CACFP centers, the prevalence of responding that role modeling eating healthy foods was "not at all difficult" was higher compared with their CACFP-participating counterparts $(\mathrm{P}=0.026)$. However, for home-based ECEs participating in CACFP as compared with non-CACFP homes, the prevalence of practice implementation 
for role modeling eating healthy foods and serving meals family-style were $8.2 \%$ and $14.6 \%$ higher, respectively ( $\mathrm{P}<0.05$ for all). This said, the only best practice to remain significantly different by CACFP participation after considering adjustment for multiple comparison was serving meals family style among home-based ECEs $(\mathrm{P}=0.002)$. Among non-CACFP home-based ECEs, there was a higher prevalence of reporting that mealtimes with children were stressful compared with those CACFP-participating; however, results were not significant after considering adjustment for multiple comparison $(\mathrm{P}=0.014$; Table 5) In both centers and home-based ECEs, CACFP participation was related to a higher prevalence of receiving professional development on nutrition $\mathrm{P}<0.012$ for both; (Table 6).

\section{Discussion}

This study described director-reported ECE program best practice implementation and associated barriers in Nebraska, in which prevalence of childhood obesity is particularly concerning. ${ }^{15}$ Results presented include associations before and after considering adjusted $\mathrm{P}$ values for multiple comparison; such results, while they may considered nonsignificant, are still hypothesis-generating by nature and warrant consideration and discussion. Findings from the present study confirm the previously reported success of CACFP in promoting a higher quality of foods served to young children, ${ }^{11,12}$ especially for CACFP-required standards for foods and beverages served. However, CACFP-participating programs did not report a significantly higher implementation of CACFP best practices than non-CACFP programs. This finding is not particularly surprising because food and beverages served are included in CACFP requirements, while specific best practices on foods and staff behaviors are not. ${ }^{25}$ This is important because implementation of best practices such as child praising, involvement, and promotion of autonomy during mealtime increases the likelihood of children accepting the nutritious foods they are served. ${ }^{26}$ To promote beneficial staff behaviors encouraging children's consumption of healthful food items, it may be necessary to include related expectations and education in state quality rating systems or licensure and/or CACFP 
requirements. This information may be particularly important for practices with lower adherence overall, such as eating the same foods as the children and serving meals family-style.

In the present sample, those participating in CACFP across both ECE contexts (center and home-based) reported lower perceived difficulty implementing best practices for serving foods and beverages and lower concern for food costs. Consistent with these findings, program directors of facilities who receive reimbursement from CACFP are less likely to report cost-related concerns as a significant barrier to providing quality foods to children. ${ }^{27}$ The amount of CACFP subsidization has previously been related to the nutritional quality of homebased ECE menus. ${ }^{12}$ However, other studies report the presence of cost-related barriers to serving healthy foods for CACFP-participating child care directors. ${ }^{27}$ Given these mixed findings, future studies should explore context-specific strategies (e.g., level of subsidization, leveraging additional resources and programs, such as farm to ECE, and food procurement and purchasing ${ }^{28}$ ) to alleviate the cost-related burden of healthy foods.

The present findings show that CACFP participation was also related to a higher frequency of receiving professional nutrition education. Studies have previously shown that meals served are more healthful when the staff is required to complete continued education on CACFP compliance. ${ }^{11,12}$ Trainings reported in the present study included in-person or online CACFP-required training but excluded training specifically on food safety or food program guidelines. However, CACFP-led nutrition training may primarily focus on instruction of reimbursement-qualifying practices vs benefit of practices to improve diet quality. For CACFP certification and renewal, ECE providers are required to attend annual nutrition training held by the Nebraska (or State) Department of Education, although required annual hours are not specified. ${ }^{29} \mathrm{~A}$ change in language and focus could potentially be considered to promote better recommended best practices and healthful mealtime behaviors.

There is a paucity of research in home-based ECEs overall compared with centers; the present results indicated that home-based ECE providers participating in CACFP were more likely to report a lack of support from other providers as a barrier to implementing best practices, although these results were no longer significant after 
adjusting for multiple comparison. As reported by the current study sample, compared with centers, home-based ECEs typically have fewer providers on staff and are more likely to have food prepared on-site, with the provider bearing responsibility for meal planning and preparation. Perceived support is a common teacher-reported barrier to promoting health for young children, ${ }^{30,31}$ and can predict successful practice implementation for caregivers of young children. ${ }^{30}$ Differing barriers to nutrition practice implementation in home-based ECEs may be attributed to additional time, scheduling, budgetary, and organizational constraints incurred from providers' multiple responsibilities, which can be intensified by lack of additional staff. ${ }^{22,33}$ These findings, in combination with previously known differences between ECE contexts, may indicate a need for additional support for homebased ECE providers, potentially through their program sponsors or specialized CACFP reimbursement.

The design of the current study is subject to limitations. Because of the cross-sectional nature of the study, causality cannot be inferred from the reported differences in proportions. Data were self-reported and could be subject to selection bias, response bias, and social desirability. This finding may be particularly important among those participating in CACFP with assumed knowledge of standards and best practices and perception of survey response being assessed for compliance. Overestimation of perceived vs actual mealtime practices (enthusiastic role modeling, family-style meal service, etc.) has been previously identified in ECE providers, potentially because of a lack of understanding of what constitutes each practice. ${ }^{34}$ Finally, responses were primarily recorded from program directors, who, on the basis of various levels of experience in classrooms, may not have complete knowledge of current classroom activities or provider barriers. This limitation may be more pertinent in centers than homebased ECEs, as home-based directors typically serve in all roles simultaneously. However, respondents were instructed to defer to the staff with the most accurate insight on that practice. Strengths of the study included the use of a large statewide sample representing both centers and home-based ECEs and the use of quantitative data derived from previous intensive qualitative work. Analyses were adjusted for multiple comparisons to control for type I error. The study objective is novel, representing a unique landscape and region of the US, and provides 
valuable insight to inform future policy development and evaluation. Furthermore, this study provides baseline data collected previous to recent changes in CACFP standards to compare future studies conducted after implementation.

\section{Implications for research and practice}

These findings can help to inform intervention and resources provided by statewide and community influencers and practitioners, particularly suggesting incentivizing training for those mealtime practices that have a lower prevalence of implementation. Although professional development groups such as the Nebraska Department of Education-Team Nutrition organization offer training specific to mealtime best practices, ${ }^{30}$ providers' motivation to attend is heavily driven by CACFP and state licensure requirements. ${ }^{35}$ Thus, these data suggest strengthening these requirements to include mealtime behaviors and potentially altering reimbursement rates and resources to assist ECEs in overcoming common context- specific barriers to implementation. Furthermore, improving CACFP enrollment through sponsored outreach programs, or strengthening state licensing to accommodate CACFP requirements and best practices, could be potential key strategies for improving nutrition-related practices in nonCACFP settings. On the basis of these findings, future research could examine (1) mixed-methods understanding of feasibility for strategies promoting mealtime best practices across ECE contexts (centers vs home-based), especially for practices least implemented; (2) influence of training and subsidization on perceptions of support for meeting nutrition practices; and (3) ECE implementation of CACFP requirements and best practices, including difficulty and barriers, after the 2017 updates to CACFP standards. Moving forward, it will be important that intervention consider context-specific barriers to promoting health for young children and provide resources to fit these needs.

Disclosure The authors have not stated any conflicts of interest. 


\section{References}

1. Lorson BA, Melgar-Quinonez HR, Taylor CA. Correlates of fruit and vegetable intakes in US children. J Am Diet Assoc. 2009;109:474-478.

2. Ventura EE, Davis JN, Alexander KE, et al. Dietary intake and the metabolic syndrome in overweight Latino children. J Am Diet Assoc. 2008;108:1355-1359.

3. Birch LL, Fisher JO. Development of eating behaviors among children and adolescents. Pediatrics. 1998;101:539-549.

4. Mikkilä V, Räsänen L, Raitakari OT, Pietinen P, Viikari J. Consistent dietary patterns identified from childhood to adulthood: the cardiovascular risk in Young Finns Study. Br J Nutr. 2005; 93:923-931.

5. Mikkilä V, Räsänen L, Raitakari OT, Pietinen P, Viikari J. Longitudinal changes in diet from childhood into adulthood with respect to risk of cardiovascular diseases: the cardiovascular Risk in Young Finns Study. Eur J Clin Nutr. 2004;58:1038-1045.

6. Laughlin L. Who's Minding the Kids? Child Care Arrangements: Spring 2011. United States Census Bureau; 2013 http://www.census.gov/prod/2013pubs/ p70-135.pdf Accessed March 22, 2019.

7. Redford J, Desrochers D, Hoyer KM. The Years Before School: Children's Nonparental Care Arrangements from 2001 to 2012. Stats in Brief. National Center for Education Statistics; 2017 https://nces.ed.gov/pubs2017/2017096. pdf Accessed March 22, 2019.

8. US Department of Agriculture. Child and Adult Care Food Program. https:// www.fns.usda.gov/cacfp Accessed March 22, 2019.

9. US Department of Agriculture. Child nutrition tables; 2018 https://www.fns. usda.gov/pd/child-nutrition-tables Accessed March 22, 2019.

10. US Department of Agriculture, US. Department of Health and Human Services. Dietary Guidelines for Americans. US Department of Agriculture and US Department of Health and Human Services; 2010 https://health.gov/sites/ default/files/2020-01/DietaryGuidelines2010.pdf Accessed March 22, 2019.

11. Erinosho T, Vaughn A, Hales D, Mazzucca S, Gizlice Z, Ward D. Participation in the child and adult care food program is associated with healthier nutrition environments at family child care homes in Mississippi. J Nutr Educ Behav. 2018;50:441-450.

12. Monsivais P, Kirkpatrick S, DB Johnson. More nutritious food is served in child-care homes receiving higher federal food subsidies. J Am Diet Assoc. 2011;111:721-726.

13. Ritchie LD, Boyle M, Chandran K, et al. Participation in the child and adult care food program is associated with more nutritious foods and beverages in child care. Child Obes. 2012;8:224-229.

14. Schwartz MB, Henderson KE, Grode G, et al. Comparing current practice to recommendations for the child and adult care food program. Child Obes. 2015;11:491-498.

15. Trust for America's Health and Robert Wood Johnson Foundation. State of 
childhood obesity in Nebraska. https://stateofchildhoodobesity.org/states/ne/ Accessed March 22, 2019.

16. Child and Adult Care Food Program. Improving Nutrition and Promoting Wellness in Childcare with CACFP. CACFP; 2012. https://frac.org/wp-content/ uploads/cacfp improving nutrition report.pdf Accessed March 22, 2019.

17. Dev DA, Garcia AS, Dzewaltowski DA, et al. Provider reported implementation of nutrition-related practices in childcare centers and family childcare homes in rural and urban Nebraska. Prev Med Rep. 2020;17:101021.

18. Roemmich JN, Epstein LH, Raja S, Yin L. The neighborhood and home environments: disparate relationships with physical activity and sedentary behaviors in youth. Ann Behav Med. 2007; 33:29-38.

19. Ammerman AS, Ward DS, Benjamin SE, et al. An intervention to promote healthy weight: nutrition and physical activity self-assessment for child care (NAP SACC) theory and design. Prev Chronic Dis. 2007;4:A67.

20. Whitaker RC, Gooze RA, Hughes CC, Finkelstein DM. A national survey of obesity prevention practices in head start. Arch Pediatr Adolesc Med. 2009; 163:1144-1150.

21. Hughes CC, Gooze RA, Finkelstein DM, Whitaker RC. Barriers to obesity prevention in head start. Health Aff (Millwood). 2010;29:454-462.

22. Nanney MS, LaRowe TL, Davey C, Frost N, Arcan C, O'Meara J. Obesity prevention in early child care settings. Health Educ Behav. 2017;44:23-31.

23. Garcia AS, Dev DA, Stage VC. Predictors of parent engagement based on child care providers' perspectives. J Nutr Educ Behav. 2018;50:905-912.

24. Midway S, Robertson M, Flinn S, Kaller M. Comparing multiple comparisons: practical guidance for choosing the best multiple comparisons test. Peer J. 2020;8:e10387.

25. Nebraska Department of Education. Child and Adult Care Food Program. https://www.education.ne.gov/ns/cacfp/ Accessed June 25, 2019.

26. Benjamin Neelon SE, Briley ME. American Dietetic Association. Position of the American Dietetic Association: benchmarks for nutrition in child care. J Am Diet Assoc. 2011;111:607-615.

27. Zaltz DA, Pate RR, O'Neill JR, Neelon B, Benjamin-Neelon SE. Barriers and facilitators to compliance with a state healthy eating policy in early care and education centers. Child Obes. 2018;14:349-357.

28. Chriqui JF, Schermbeck RM, Leider J. Food purchasing and preparation at child day care centers participating in the child and adult care food program in the United States, 2017. Child Obes. 2018;14:375-385.

29. Nebraska Department of Education. CACFP annual update. https://www. education.ne.gov/ns/training/cacfptraining/cacfp-annual-update/ Accessed March 22, 2019.

30. Halloran KM, Gorman K, Fallon M, Tovar A. Nutrition knowledge, attitudes, and fruit and vegetable intake as predictors of head start teachers' classroom mealtime behaviors. J Nutr Educ Behav. 2018;50:340-348.

31. Metos JM, Sarnoff K, Jordan KC. Teachers' perceived and desired roles in 
nutrition education. J Sch Health. 2019; 89:68-76.

32. Dev DA, Carraway-Stage V, Schober DJ, McBride BA, Kok CM, Ramsay S. Implementing the academy of nutrition and dietetics benchmarks for nutrition education for children: child-care providers' perspectives. J Acad Nutr Diet. 2017;117:1963-1971.e2.

33. Lindsay AC, Salkeld JA, Greaney ML, Sands FD. Latino family childcare providers' beliefs, attitudes, and practices related to promotion of healthy behaviors among preschool children: a qualitative study. J Obes. 2015;2015: 409742.

34. Fallon M, Halloran K, Gorman K, Ward D, Greene G, Tovar A. Self-reported and observed feeding practices of Rhode Island head start teachers: knowing what not to do. Appetite. 2018;120:310-317.

35. Dev DA, Garcia AS, Tovar A, et al. Contextual factors influence professional development attendance among child care providers in Nebraska. J Nutr Educ Behav. 2020;52: 270-280.

Tables 1-6 follow. 
Table 1. Child Care Center Characteristics, by Child Care Context and CACFP Participation $(N=1,345)$

\begin{tabular}{|c|c|c|c|c|}
\hline \multirow[b]{2}{*}{ Child Care Center Characteristics } & \multicolumn{2}{|c|}{ Center-Based Care $(n=292)$} & \multicolumn{2}{|c|}{ Family Child Care Home $(n=1,053)$} \\
\hline & $\begin{array}{l}\text { CACFP } \\
(n=198)\end{array}$ & $\begin{array}{l}\text { Non-CACFP } \\
(n=94)\end{array}$ & $\begin{array}{l}\text { CACFP } \\
(n=970)\end{array}$ & $\begin{array}{l}\text { Non-CACFP } \\
(n=83)\end{array}$ \\
\hline \multicolumn{5}{|l|}{ Average no. of children in the program (mean \pm SD) } \\
\hline $0-23$ months & $15.6 \pm 10.8$ & $15.5 \pm 14.7$ & $2.3 \pm 1.2$ & $2.0 \pm 0.9$ \\
\hline $24-35$ months & $13.0 \pm 9.3$ & $15.3 \pm 13.8$ & $2.3 \pm 1.4$ & $2.2 \pm 1.1$ \\
\hline $3-5$ years & $26.0 \pm 17.8$ & $32.7 \pm 22.5$ & $3.3 \pm 1.8$ & $3.4 \pm 1.6$ \\
\hline Older than 5 years & $18.2 \pm 20.4$ & $14.6 \pm 18.9$ & $2.3 \pm 1.8$ & $2.4 \pm 2.1$ \\
\hline \multicolumn{5}{|c|}{ Average no. of children per racial background (mean \pm SD) } \\
\hline American Indian or Alaskan Native & $2.3 \pm 7.6$ & $0.9 \pm 2.4$ & $0.3 \pm 1.0$ & $0.2 \pm 0.8$ \\
\hline Asian & $1.7 \pm 2.5$ & $2.2 \pm 2.8$ & $0.1 \S 0.5$ & $0.0 \pm 0.0$ \\
\hline Black or African American & $7.6 \pm 14.1$ & $3.2 \pm 5.3$ & $0.9 \pm 2.0$ & $1.1 \pm 3.1$ \\
\hline Native Hawaiian or Pacific Islander & $0.4 \pm 1.0$ & $0.3 \pm 1.5$ & $0.1 \pm 0.6$ & $0.0 \pm 0.2$ \\
\hline White & $50.3 \pm 38.4$ & $59.7 \pm 40.1$ & $7.7 \pm 3.3$ & $7.6 \pm 3.1$ \\
\hline Mixed Race & $7.5 \pm 8.2$ & $5.0 \pm 7.5$ & $1.1 \pm 1.6$ & $0.8 \pm 1.2$ \\
\hline Other & $4.0 \pm 7.9$ & $11.2 \pm 38.2$ & $0.2 \pm 1.3$ & $0.6 \pm 2.2$ \\
\hline Average no. of providers (mean \pm SD) & $16.1 \pm 11.6$ & $17.0 \pm 13.6$ & $1.3 \pm 1.2$ & $1.3 \pm 0.7$ \\
\hline \multicolumn{5}{|l|}{ Program schedule (\%) } \\
\hline Half-day & 0.5 & 3.2 & 0.1 & 0.0 \\
\hline Full-day & 69.7 & 59.6 & 78.1 & 62.7 \\
\hline Both half-day and full-day & 24.7 & 29.8 & 18.0 & 34.9 \\
\hline Other & 1.5 & 3.2 & 1.8 & 0.0 \\
\hline \multicolumn{5}{|l|}{ Food prepared on-site (\%) } \\
\hline Yes & 72.2 & 56.4 & 98.6 & 95.2 \\
\hline No & 14.1 & 29.8 & 0.5 & 0.0 \\
\hline Both yes and no & 13.6 & 11.7 & 0.9 & 4.8 \\
\hline \multicolumn{5}{|l|}{ Responsible for menu planning (\%) } \\
\hline Owner of child care program & 27.8 & 31.9 & 63.1 & 54.2 \\
\hline Director or site supervisor/manager & 44.4 & 48.9 & 3.6 & 4.8 \\
\hline Family child care provider & 1.0 & 0.0 & 46.5 & 59.0 \\
\hline Cook or chef & 42.4 & 29.8 & 1.0 & 1.2 \\
\hline Catering company & 15.7 & 16.0 & 0.2 & 0.0 \\
\hline Dietitian & 4.5 & 3.2 & 0.2 & 0.0 \\
\hline Parent/guardians provide food for their children & 1.0 & 9.6 & 0.1 & 3.6 \\
\hline Go NAP SACC participation (\% yes) & 39.4 & 23.4 & 11.0 & 12.0 \\
\hline Nebraska Step Up to Quality participation (\% yes) & 38.9 & 19.1 & 8.8 & 9.6 \\
\hline NAEYC member (\% yes) & 15.2 & 13.8 & 5.7 & 6.0 \\
\hline
\end{tabular}

CACFP indicates Child and Adult Care Food Program; Go NAP SACC, Nutrition and Physical Activity Self-Assessment in Child Care; NAEYC, National Association for the Education of Young Children

a. Director/provider was given the response option to select all that apply. 


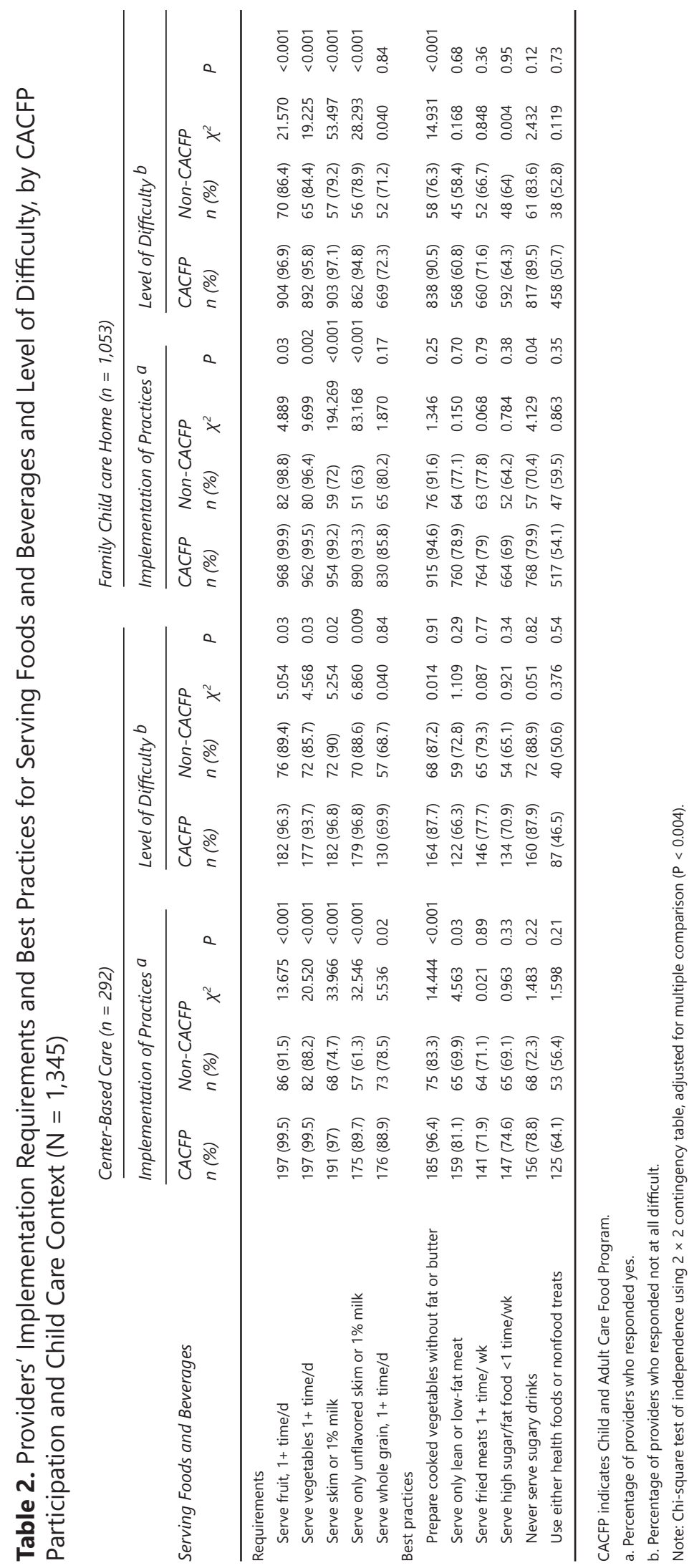




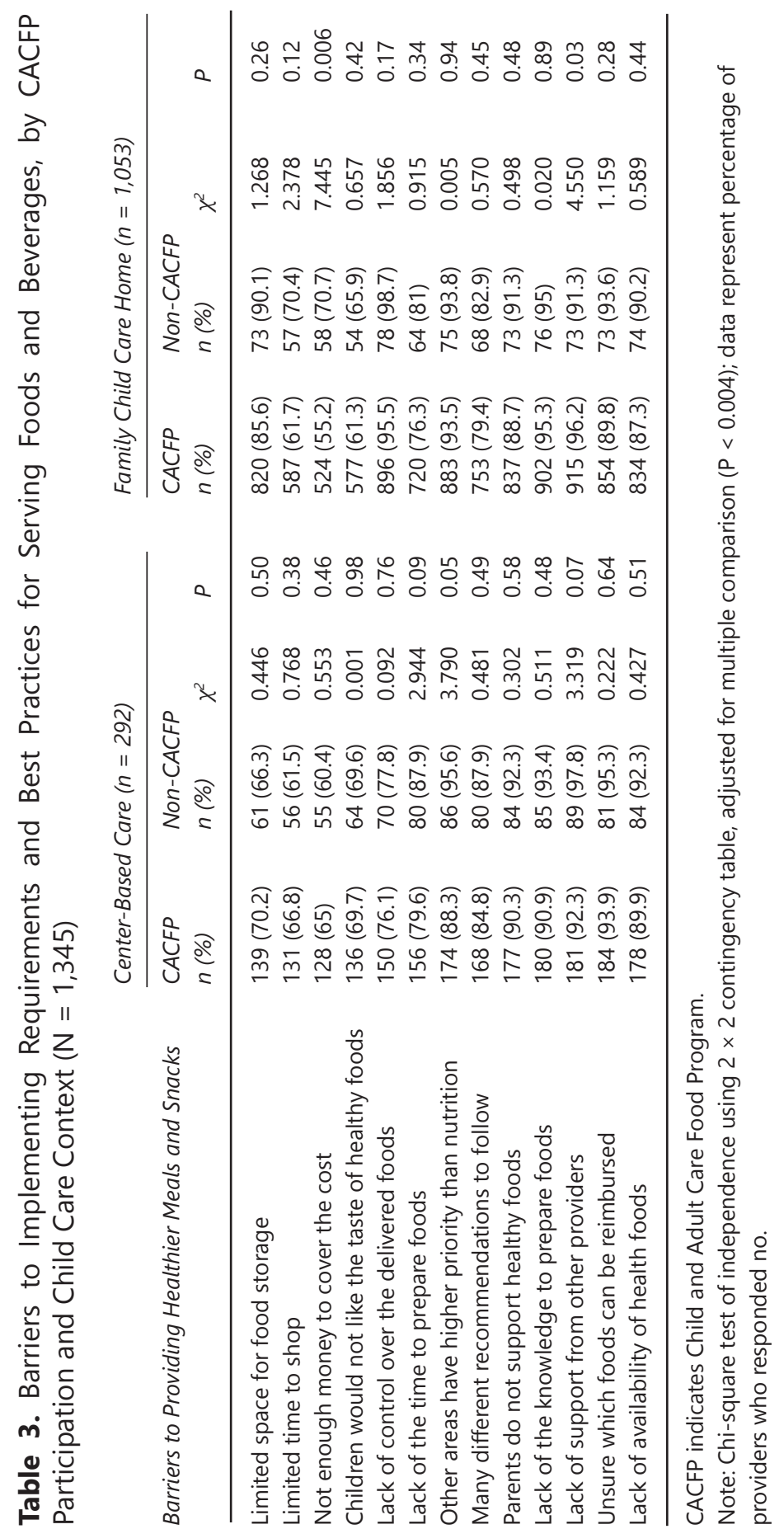




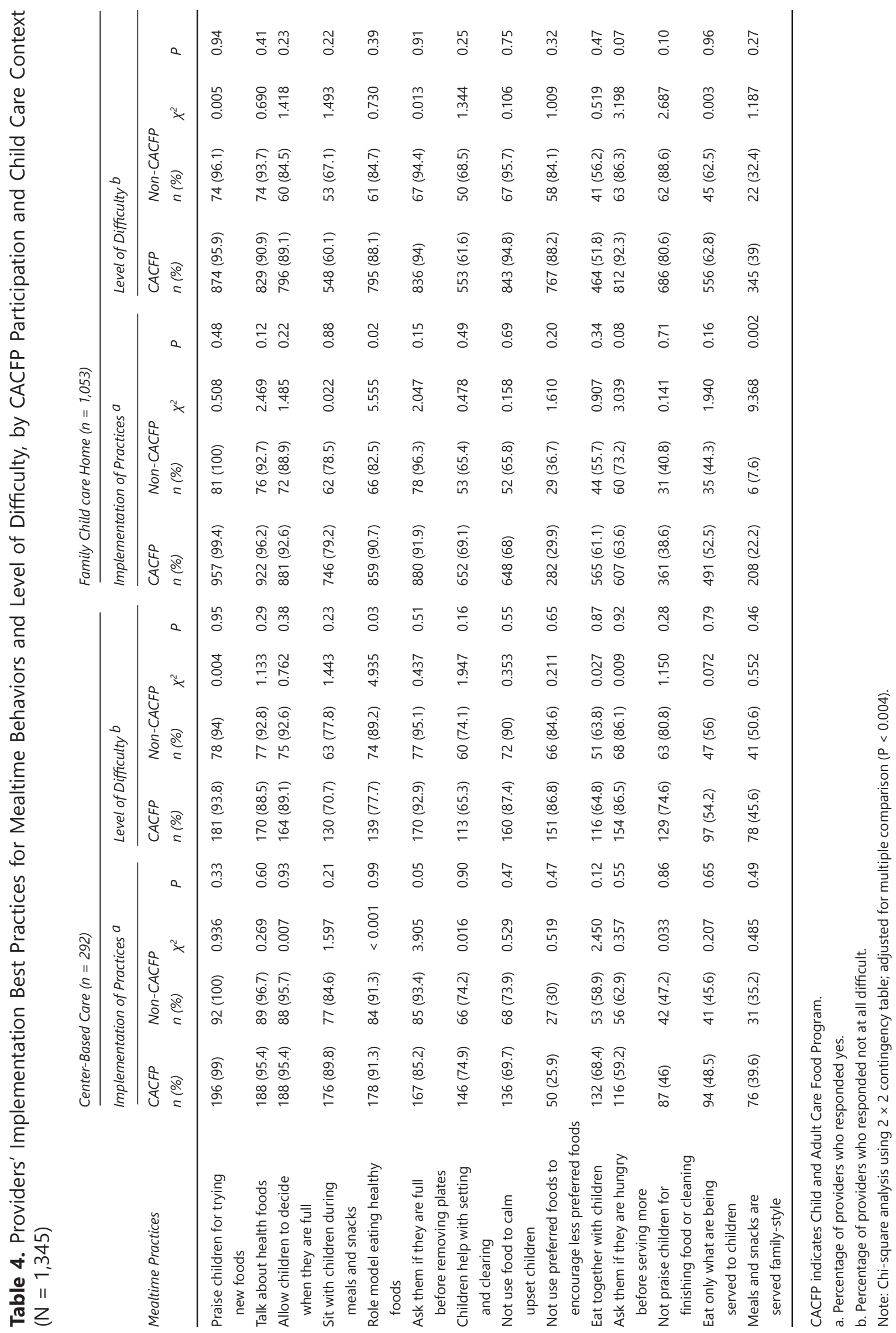




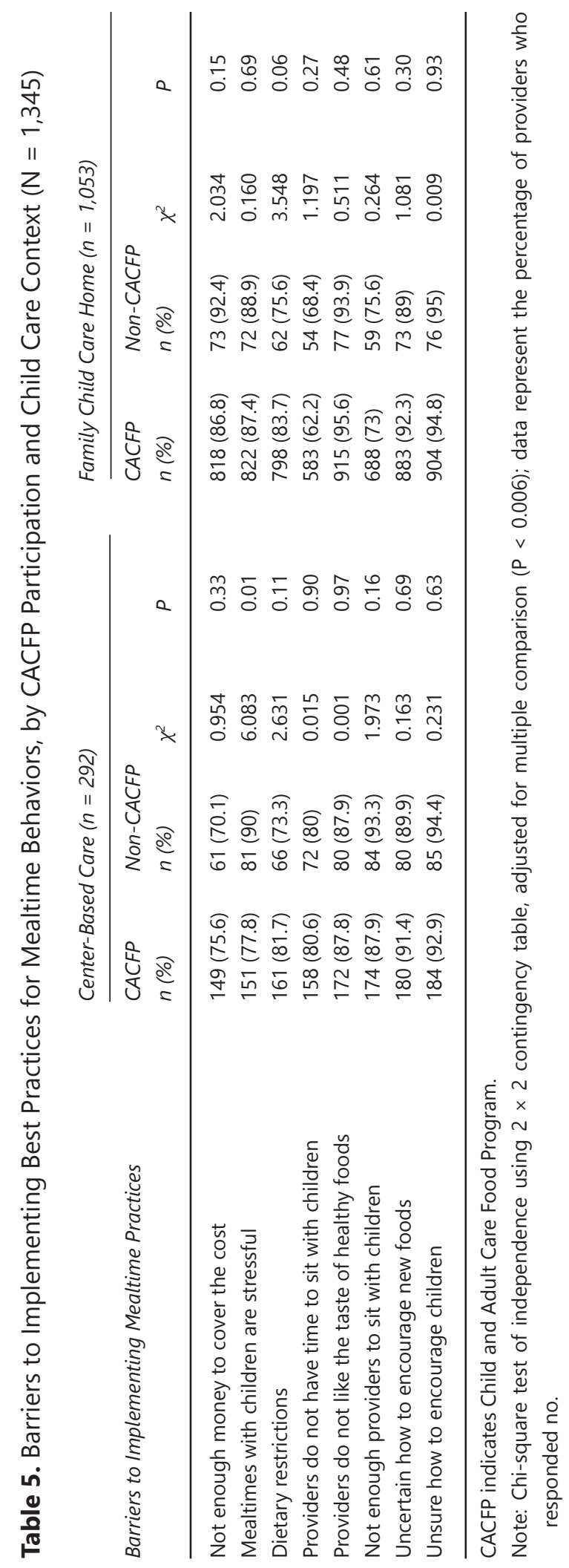




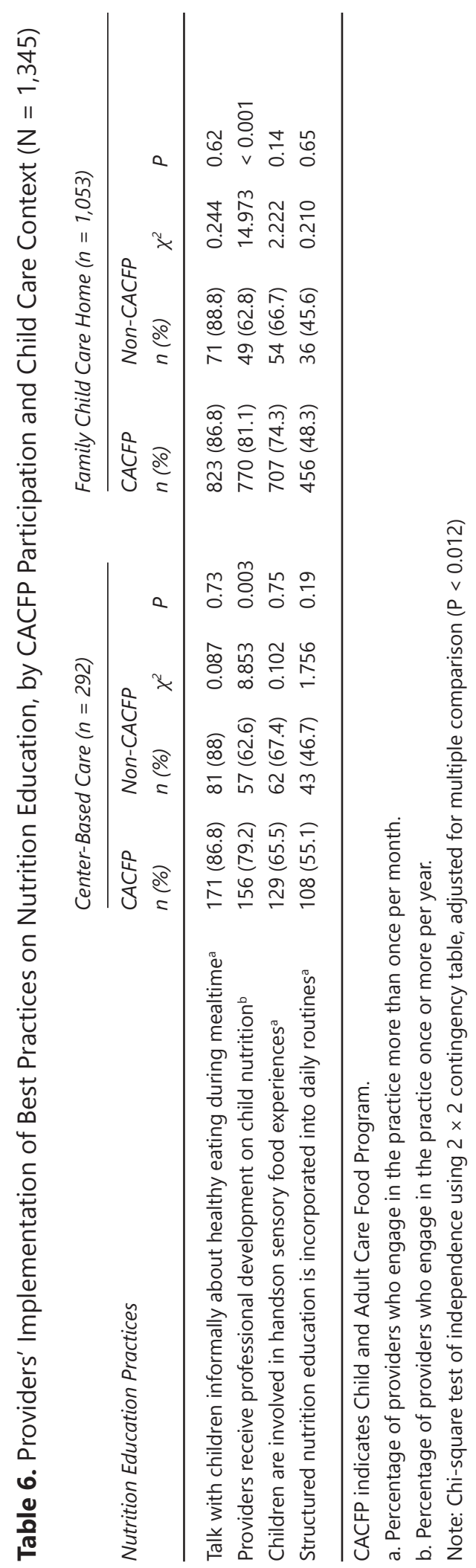

